\title{
Comparison of Azerbaijan and other seismic codes
}

\author{
L. Zeynalov ${ }^{1,2}$, I. Polukhov ${ }^{1,2}$ \& M. Gölalmış ${ }^{2,3}$ \\ ${ }^{1}$ Azerbaijan University of Architecture and Construction, Azerbaijan \\ ${ }^{2}$ The Ministry of Emergency Situations of Azerbaijan, \\ State Agency for Control of the Construction Safety, \\ General Department of State Expertise, Azerbaijan \\ ${ }^{3}$ Met Dizayn, Azerbaijan
}

\begin{abstract}
Azerbaijan, a post-soviet country, has recently become one of the most economically developed countries in the former USSR region. Many unique buildings, as well as high rise buildings, have been designed and constructed by renowned European, USA and Asian companies in the last decade. Seismic levels of Azerbaijan territory which is located in an Alpine folded system at the crossroads of Western Asia and Eastern Europe are very high. Many strong and catastrophic earthquakes have happened there so far. The former USSR seismic code was used in Azerbaijan until the new Azerbaijan seismic design code (AzDTN) was issued in 2009. This paper compares AzDTN with Japanese (BSL), the former USSR (SNIP II-7-81), USA (UBC97/IBC2006) and European (EC8) seismic design codes. Soil classification, building behavior factor and unreduced design elastic spectra are compared, differences and similarities are discussed. Unreduced design elastic spectra drawn as per AzDTN is more or less similar to ones drawn as per other seismic design codes. Two concrete buildings which are 7-story and 16-story with moment resistance structural systems are examined, and their seismic base shear coefficients calculated using equivalent lateral force procedures according to AzDTN and other codes are compared. As behavior factors specified in AzDTN and BSL for concrete buildings are close to each other, the calculated seismic base shear coefficients for the two buildings are resulted in relatively similar but are larger than UBC97/IBC2006, SNIP II-781 and EC8.

Keywords: Azerbaijan seismic code, earthquake, seismic codes, shear velocity, unreduced response spectra, base shear.
\end{abstract}




\section{Introduction}

Azerbaijan is the largest country located in the Caucasus at the cross road of Western Asia and Eastern Europe. More than half of Azerbaijan is rich in oil and natural gas [1]. Using the incomes of these natural resources, it is developing economically fast, and making big investments in contraction area too.

Azerbaijan is located in an active seismic region, and structural seismic designs are vital to the scheme development. The former USSR seismic code (Snip) [2] was used in the design of structures until the first Azerbaijan Seismic Code (AzDTN) [3] was officially issued in 2009. Engineers benefited from experience of other countries seismic codes and tried to adapt them into structural designs in Azerbaijan until 2009 [4, 5].

This paper introduces an overview of AzDTN and compares it with the former USSR (Snip), Japanese (BSL) [6], European (EC8) [7] and the United States (UBC97/IBC2006) [8, 9] seismic codes. It consists of four parts. The first part deals with the soil classifications. The second part examines the behavior factors. Third, comparison is made for the unreduced elastic spectra including soil classifications. The last part compares seismic base shear coefficients of 7story and 16-story buildings.

\section{Soil classification}

Seismic ground response properties depend on site soil conditions and seismic intensities. The easiest way for engineers is to take these values from codes according to site soil investigation data and then to use in engineering projects. Soil classifications defined in codes mainly depends on shear wave velocities and Standard Penetration Test Results $\left(\mathrm{N}_{\mathrm{SPT}}\right)$ which can be evaluated between soil layers from $30 \mathrm{~m}$ below the base of foundation level as follows

$$
\begin{gathered}
V_{s, 30=}=\frac{30}{\sum_{i=1}^{n} \frac{h_{i}}{V_{i}}} \\
N_{S P T=} \frac{30}{\sum_{i=1}^{n} \frac{h_{i}}{N_{S P T}}}
\end{gathered}
$$

where, $n$ is the number of soil layers, $h_{i}$ is the thickness of the $i$-th soil layer in meters, $V_{i}$ is the shear wave propagation velocity of the $i$-th soil layer, and $\mathrm{N}_{\mathrm{SPT}}$ is Standard Penetration Test blow number of the i-th soil layer.

Four soil types, defined as I, II, III and IV are specified in AzDTN with respect to soil wave velocities (Table 1). Soil I and Soil IV represent hard soil $(\mathrm{Vs}>800 \mathrm{~m} / \mathrm{s})$ and soft soil $((\mathrm{Vs}<180 \mathrm{~m} / \mathrm{s})$ respectively. Soil II and Soil III have intermediate properties and their wave velocities changes between $180 \mathrm{~m} / \mathrm{s}$ and $800 \mathrm{~m} / \mathrm{s}$.

Soil characteristics defined in AzDTN code according to shear wave velocity and $\mathrm{N}_{\mathrm{SPT}}$ are almost same as soil characteristics as in EC8 cand UBC97/2006. 
The difference between both codes is that two soil types which are $\mathrm{S}_{\mathrm{B}}$ and $\mathrm{S}_{\mathrm{A}}$ are defined when $\mathrm{V}_{\mathrm{s}}$ is greater than $800 \mathrm{~m} / \mathrm{s}$ in UBC97/IBC2006.

Soil characteristics specified in AzDTN code are comparable to those in Snip which defines three soil types. Snip does not classify soils according to $\mathrm{V}_{\mathrm{s}}$ and $\mathrm{N}_{\text {SPT }}$ values; it classifies soils according to consistency index, porosity ratios, etc. These parameters in both codes for soil types I, II and III are the same. Accordingly, three soil type shear wave velocities are predicted for Snip (Table 1).

Three soil types in BSL are defined based on soil fundamental periods, where hard, medium and soft soils' fundamental periods are specified as $\mathrm{T}<0.2 \mathrm{~s}$, $0.2 \mathrm{~s}<\mathrm{T}<0.6 \mathrm{~s}$ and $\mathrm{T}>0.6 \mathrm{~s}$ respectively. The corresponding shear wave velocities assuming soil characteristic comparison herein carried out using a unique soil with $30 \mathrm{~m}$ thickness are calculated by eqn (3) [10],

$$
V_{s, 30=} \frac{4 * h i}{T}
$$

where $h_{i}$ and $T$ represent the unique soil thickness of $30 \mathrm{~m}$ and the soil fundamental period. Using eqn(3), shear wave velocity for hard, medium and soft soils in BJC are calculated as $\mathrm{V}_{\text {s_hard }}>600 \mathrm{~m} / \mathrm{s}, 600 \mathrm{~m} / \mathrm{s}>\mathrm{V}_{\mathrm{s}_{-} \text {medium }}>200 \mathrm{~m} / \mathrm{s}$ and $\mathrm{V}_{\text {s_soft }}<200 \mathrm{~m} / \mathrm{s}$ respectively. The hard and soft soil types in AzDTN and BSL have almost same soil properties; however, soil types II and III in AzDTN correspond nearly to soil type II in BSL (Table 1).

Table 1: Soil classification comparison between AzDTN and worldwide codes.

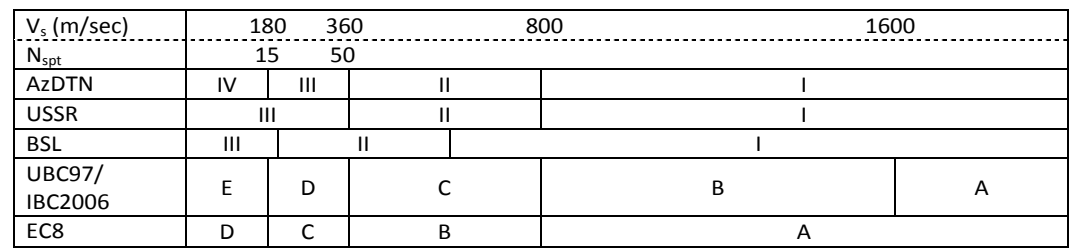

\section{Building behavior factors}

Building/structure behavior factors are defined with $\mathrm{K}_{2}$ coefficient in AzDTN (Table 2) which is the inverse of building behavior factors defined in EC8 and UBC97/IBC 2006. It is categorized into three parts in AzDTN similar to Snip. The first building type behaviour is completely elastic under seismic load, and any residual deformations and damages are not allowed. $\mathrm{K}_{2}$ factor specified for this kind of structure is "1.0" (Table 2). The second building type behaves plastically under seismic load, and some residual deformations which do not result in any damage to people and properties are allowed. $\mathrm{K}_{2}$ factors ranging between 0.25 and 0.6 for these types of structures are specified according to building structural system types (Table 2). The third types generally consists of one story less important industrial, agricultural and storage buildings. If damage occurs, permanent cracks, movements, etc. after an earthquake this does not 
jeopardize people's safety, $\mathrm{K}_{2}$ factor used for the third kind of building type is 0.3 (Table 2). Building/structure behavior factors specified in AzDTN and SNIP are similar, except the third class structures for that 0.12 is specified in SNIP.

Building/structures are categorized as per frame ductility levels (moment resisting levels) in BSL, EC8 and UBC97/IBC2006 as well as their structural system types.

Table 2: $\quad$ Building/structure behavior factor [3].

\begin{tabular}{|c|c|c|}
\hline No & Building solutions & $\begin{array}{c}\mathrm{K}_{2}-\text { value of } \\
\text { coefficient }\end{array}$ \\
\hline 1 & Damage or inelastic deformation is not allowed. & $1.0\left(1 / \mathrm{K}_{2}=1.00\right)$ \\
\hline \multirow{7}{*}{2} & $\begin{array}{l}\text { Permanent deformations and damage may be allowed, } \\
\text { - steel frame }\end{array}$ & $0.25\left(1 / \mathrm{K}_{2}=4.00\right)$ \\
\hline & $\begin{array}{l}\text { - concrete frame without vertical diaphragms or } \\
\text { connections }\end{array}$ & $0.35\left(1 / \mathrm{K}_{2}=2.86\right)$ \\
\hline & -concrete frame with diaphragms or connections & $0.30\left(1 / \mathrm{K}_{2}=3.33\right)$ \\
\hline & - reinforced panel and large-monolithic reinforced walls & $0.25\left(1 / \mathrm{K}_{2}=4.00\right)$ \\
\hline & $\begin{array}{l}\text { - bearing wall made of large blocks and reinforced } \\
\text { frame- stone system }\end{array}$ & $0.40\left(1 / K_{2}=2.50\right)$ \\
\hline & - Brick or masonry & $0.45\left(1 / \mathrm{K}_{2}=2.22\right)$ \\
\hline & - Pillars of the seismic systems & $0.60\left(1 / \mathrm{K}_{2}=1.67\right)$ \\
\hline 3 & Few Liability buildings and facilities, & $0.3\left(1 / \mathrm{K}_{2}=3.33\right)$ \\
\hline
\end{tabular}

The BSL structural characteristic factors $\left(D_{s}\right)$ are determined for moment resisting frames with reference to member ductility levels which are excellent, good, fair and poor. The smallest $D_{s}$ value of 0.25 is specified for excellent ductile steel frames; conversely, the highest $D_{\mathrm{s}}$ value of 0.55 is specified for the poorer ductile moment frames (see Table 3).

Table 3: $\quad$ Structural characteristic factor* (Ds).

\begin{tabular}{|c|c|c|c|}
\hline \multirow{2}{*}{$\begin{array}{c}\text { Ductility Behavior of } \\
\text { Members }\end{array}$} & \multicolumn{3}{|c|}{ Frame Type } \\
\cline { 2 - 4 } & $\begin{array}{c}\text { (1) Ductile Moment } \\
\text { Frame }\end{array}$ & $\begin{array}{c}\text { (2) Frame other than } \\
\text { listed in (1)\&(3) }\end{array}$ & $(3)^{* *}$ \\
\hline Excellent & 0.30 & 0.35 & 0.40 \\
\hline Good & 0.35 & 0.40 & 0.45 \\
\hline Fair & 0.40 & 0.45 & 0.50 \\
\hline Poor & 0.45 & 0.50 & 0.55 \\
\hline
\end{tabular}

*The values can be decreased by 0.05 for steel frame reinforced concrete or steel buildings.

**Frames with shear with shear walls or braces for reinforced concrete and steel frame reinforced concrete buildings, and frames with compressive braces for steel buildings.

European Seismic Code (EC8) classifies structures in three ductility classes, low (DCL), medium (DCM) and high $(\mathrm{DCH})$ with reference to the available ductility of their members. Behavior factors defined for DCM and DCH in EC8 are given in Table 4. The upper q values for DCM and DCH are stated as 4.0 and 6.5 in EC8 for a structure having a regular plan view and elevation. 
Table 4: $\quad$ Behavior factors " $q$ " specified in EC8.

\begin{tabular}{|l|c|c|}
\hline STRUCTURAL TYPE & DCM & DCH \\
\hline Frame, dual and coupled wall systems & $3.0 \alpha_{\mathrm{u}} / \alpha_{1}$ & $4.5 \alpha_{\mathrm{u}} / \alpha_{1} *$ \\
\hline Uncoupled wall system & 3.0 & $4.0 \alpha_{\mathrm{u}} / \alpha_{1}$ \\
\hline Torsionally flexible system & 2.0 & 3.0 \\
\hline Inverted pendulum system & 1.5 & 2.0 \\
\hline
\end{tabular}

* The values can be increased to $5.0 \alpha_{v} / \alpha_{1}$ for steel moment resisting frames in Table 6.2_EC8.

$* * \alpha_{\mathrm{u}} / \alpha_{1}$ ranges between 1.1 and 1.3 for a building regular in plan.

Three moment resisting frame levels which are special, intermediate and ordinary are defined in UBC97/IBC2006 for buildings and structures. With respect to moment resisting levels and structural system types, response modification coefficients $(\mathrm{R})$ are specified as 5.0-8.5 for special, 4.5-6.5 for intermediate and 3.0-5.0 for ordinary frames (Table 5).

Table 5: Upper limit response modification coefficient " $R$ " stated in UBC97/IBC2006.

\begin{tabular}{|l|c|c|c|}
\hline STRUCTURAL TYPE & SMRF & IMRF & OMRF \\
\hline A-Bearing Wall System & 5.0 & - & 4.0 \\
\hline B-Building Frame System & $7.0-8.0$ & 5.0 & 5.0 \\
\hline C-Moment Resisting Frame System & $8.0-8.5$ & 5.0 & 3.0 \\
\hline D-Dual system & $8.0-8.5$ & 6.5 & 4.5 \\
\hline
\end{tabular}

\section{Unreduced elastic spectra}

Elastic spectrum graphs and soil amplification coefficients defined in codes are main parameters determining impacted seismic forces on structures. These factors are developed after a lot of research.

Unreduced elastic spectrum of AzDTN and other codes' spectra are drawn and compared as follows

\section{Unreduced Elastic Spectra of AzDTN with soil factors}

$$
\frac{\mathrm{S}_{e}}{\mathrm{~g}}=\beta x k_{q}
$$

where $\beta$ is the elastic response spectrum and $\mathrm{kq}$ is the soil factor (Table 6 ). $\beta_{\mathrm{i}}$ is $1+1.5 \times \mathrm{T}_{\mathrm{i}} / \mathrm{T}_{\mathrm{A}}$ when $0 \leq \mathrm{T}_{\mathrm{i}} \leq \mathrm{T}, 2.5$ when $\mathrm{T}_{\mathrm{A}}<\mathrm{Ti} \leq \mathrm{T}_{\mathrm{B}}$, and $2.5 \mathrm{x}\left(\mathrm{T}_{\mathrm{B}} / \mathrm{Ti}\right)$ when $\mathrm{T}_{\mathrm{B}}<\mathrm{T}_{\mathrm{i}}$. The elastic spectra drawn for three soil classes according to Snip code are set out in Figure 1(a).

\section{Unreduced Elastic Spectra of SNIP with soil factors}

$$
\frac{\mathrm{S}_{e}}{\mathrm{~g}}=\beta x k_{\text {soil }}
$$


where $\beta$ is the elastic response spectrum which is $1.0 / T_{i}$ not more than 3 for soil type I, $1.1 / \mathrm{T}_{\mathrm{i}}$ not more than 2.7 for soil type II, and $1.5 / \mathrm{T}_{\mathrm{i}}$ not more than 3 for soil type III. Three soil classes are defined in Snip but soil factors are not specified clearly as in AzDTN. In place of soil factors, site seismic intensity according to soil factors increases or decreases in codes. For example, if a site soil class is "III", the site seismic intensity increases one point as per Snip code and the site seismic design acceleration value doubles also. If a site soil class is "I", the site's seismic intensity decreases one point and the site seismic design acceleration value halves. According to this interpretation, soil factor $\left(\mathrm{k}_{\text {soil }}\right)$ of Snip code is calculated and given in Table 7.The elastic spectra drawn for three soil classes according to Snip are set out in Figure 1 (b).

Table 6: $\quad$ Spectral acceleration constant limit periods and soil amplification coefficients $\left(\mathrm{k}_{\mathrm{q}}\right)$.

\begin{tabular}{c|c|c|c|}
\hline Soil classes & $\begin{array}{c}\mathrm{T}_{\mathrm{A}} \\
(\mathrm{sec})\end{array}$ & $\begin{array}{c}\mathrm{T}_{\mathrm{B}} \\
(\mathrm{sec})\end{array}$ & $\mathrm{k}_{\mathrm{q}}$ \\
\hline I & 0.10 & 0.40 & 0.6 \\
\hline II & 0.10 & 0.40 & 1.0 \\
\hline III & 0.10 & 0.60 & 1.2 \\
\hline IV & 0.10 & 0.80 & 1.6 \\
\hline
\end{tabular}

Table 7: $\quad$ Spectral acceleration constant limit periods and soil amplification coefficients $\left(\mathrm{k}_{\mathrm{q}}\right)$.

\begin{tabular}{c|c|c|c}
\hline Soil classes & $\begin{array}{c}\mathrm{T}_{\mathrm{A}} \\
(\mathrm{sec})\end{array}$ & $\begin{array}{c}\mathrm{T}_{\mathrm{B}} \\
(\mathrm{sec})\end{array}$ & $\mathrm{k}_{\text {soil }}$ \\
\hline I & 0.10 & 0.40 & 0.5 \\
\hline II & 0.10 & 0.40 & 1.0 \\
\hline III & 0.10 & 0.80 & 2 \\
\hline
\end{tabular}

\section{Unreduced Elastic Spectra of BSL}

BSL does not stipulate any soil amplification factor but specifies critical period $\left(\mathrm{T}_{\mathrm{c}}\right)$ for Soil I, II and III as $0.4 \mathrm{sec}, 0.6 \mathrm{sec}$ and $0.8 \mathrm{sec}$, respectively. $\mathrm{R}_{\mathrm{t}}$ is developed in BSL with reference to a PGA equal to $0.4 \mathrm{~g}$. In order to compare BSL code with others, it is multiplied by $2.5(=1 / 0.4)$ which is identical to that stated in AzDTN, SNIP and EC8. The BSL unreduced elastic spectra then is calculated as follows,

$$
\frac{\mathrm{S}_{e}}{\mathrm{~g}}=R_{t} \times 2.5
$$

where $\mathrm{R}_{\mathrm{t}}$ is $1.0-0.2\left(\mathrm{~T} / \mathrm{T}_{\mathrm{C}}-1\right)^{2}, 1-0.2\left(\mathrm{~T} / \mathrm{T}_{\mathrm{c}}-1\right)^{2}$ when $\mathrm{T}_{\mathrm{c}}<\mathrm{T} \leq 2 \mathrm{~T}_{\mathrm{c}}$, and $1.6 \mathrm{~T}_{\mathrm{c}} / \mathrm{T}$ when $2 \mathrm{~T}_{\mathrm{c}}<\mathrm{T}$. The elastic spectra drawn for three soil classes according to BSL code are set out in Figure 1(c). 


\section{Unreduced Elastic Spectra of EC8 with soil factors}

$$
\frac{\mathrm{S}_{e}}{\mathrm{~g}}=S x S_{e}(T)
$$

where $\mathrm{S}_{\mathrm{e}}(\mathrm{T})$ is $1.0+\mathrm{T} / \mathrm{T}_{\mathrm{B}} \mathrm{x}(2.5 \eta-1)$ when $0 \leq \mathrm{T} \leq \mathrm{T}_{\mathrm{B}}, 2.5 \eta$ when $\mathrm{T}_{\mathrm{B}} \leq \mathrm{T} \leq \mathrm{T}_{\mathrm{C}}$, $2.5 \eta \times \mathrm{T}_{\mathrm{c}} / \mathrm{T}$ when $\mathrm{T}_{\mathrm{C}} \leq \mathrm{T} \leq \mathrm{T}_{\mathrm{D}}$, and $2.5 \eta \times \mathrm{T}_{\mathrm{C}} \mathrm{T}_{\mathrm{D}} / \mathrm{T}^{2}$ when $\mathrm{T}_{\mathrm{D}} \leq \mathrm{T} \leq 4.0 \mathrm{~s}$. $\eta$ is damping correction factor used as 1.0 and $\mathrm{S}$ is the soil factor (Table 8). The elastic spectra drawn according to EC8 for four soil classes are set out in Figure 1(d).

Table 8: $\quad$ Spectral acceleration constant limit periods and soil amplification coefficients (S) for Type 1 elastic response spectra.

\begin{tabular}{|c|c|c|c|}
\hline Soil classes & $\mathrm{S}$ & $\begin{array}{c}\mathrm{T}_{\mathrm{A}} \\
(\mathrm{sec})\end{array}$ & $\begin{array}{c}\mathrm{T}_{\mathrm{B}} \\
(\mathrm{sec})\end{array}$ \\
\hline $\mathrm{A}$ & 1.0 & 0.15 & 0.40 \\
\hline $\mathrm{B}$ & 1.2 & 0.15 & 0.50 \\
\hline $\mathrm{C}$ & 1.15 & 0.20 & 0.60 \\
\hline $\mathrm{D}$ & 1.35 & 0.20 & 0.80 \\
\hline
\end{tabular}

\section{Unreduced Elastic Spectra of UBC97/IBC2006}

$$
\begin{gathered}
\frac{\mathrm{S}_{e}}{\mathrm{~g}}=C a+\frac{1.5 C a}{T_{0}} x T \quad 0<\mathrm{T}<\mathrm{T}_{0} \\
\frac{\mathrm{S}_{e}}{\mathrm{~g}}=2.5 C a \quad \mathrm{~T}_{0}<\mathrm{T}<\mathrm{T}_{\mathrm{s}} \\
\frac{\mathrm{S}_{e}}{\mathrm{~g}}=2.5 \frac{C v}{T} \quad \mathrm{~T}_{\mathrm{s}}<\mathrm{T}
\end{gathered}
$$

where $C_{a}$ is the spectral acceleration parameter at short period, and $C_{v}$ is the spectral acceleration parameters at a period of $1.0 \mathrm{sec} . \mathrm{C}_{\mathrm{a}}$ and $\mathrm{C}_{\mathrm{v}}$ including soil parameters according to UBC97 shown in Table 9 are developed with reference to a PGA value equal to $0.4 \mathrm{~g}$ like BSL code. That's why they are multiplied in eqn $(7 \mathrm{a}, \mathrm{b}$ and $\mathrm{c})$ by 2.5 so as to make identical to other codes. The elastic spectra drawn for four soil classes are set out according to UBC97/IBC2006 shown in Figure 1(e).

Table 9: $\quad \mathrm{C}_{\mathrm{a}}$ and $\mathrm{C}_{\mathrm{v}}$ values.

\begin{tabular}{c|c|c|c|c}
\hline Soil classes & $\mathrm{T}_{0}(\mathrm{sec})$ & $\mathrm{T}_{\mathrm{S}}(\mathrm{sec})$ & $\mathrm{Ca}$ & $\mathrm{CV}$ \\
\hline $\mathrm{S}_{\mathrm{A}}$ & 0.080 & 0.40 & 0.32 & 0.32 \\
\hline $\mathrm{S}_{\mathrm{B}}$ & 0.080 & 0.4 & 0.40 & 0.4 \\
\hline $\mathrm{S}_{\mathrm{C}}$ & 0.112 & 0.56 & 0.40 & 0.56 \\
\hline $\mathrm{S}_{\mathrm{D}}$ & 0.116 & 0.58 & 0.44 & 0.64 \\
\hline $\mathrm{S}_{\mathrm{E}}$ & 0.213 & 1.07 & 0.36 & 0.96 \\
\hline \hline
\end{tabular}




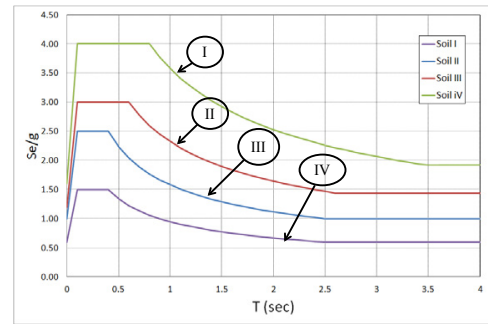

a) AzDTN

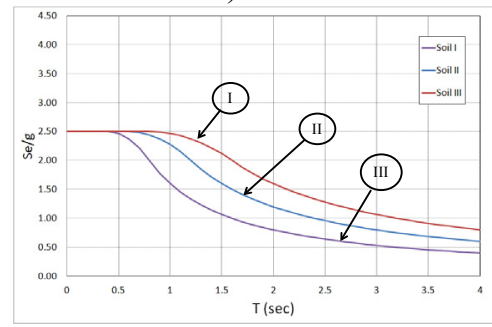

c) BSL

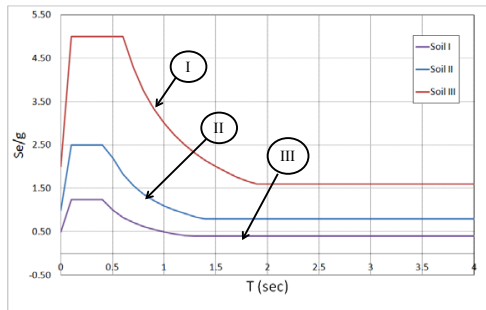

b) Snip

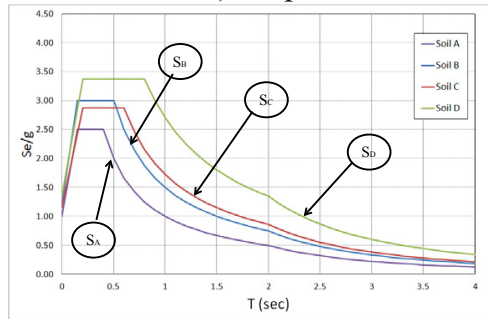

d) $\mathrm{EC} 8$

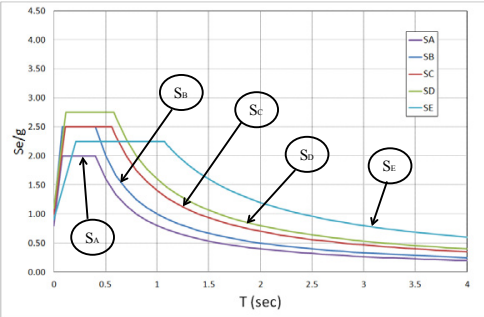

e) UBC97

Figure 1: Unreduced Elastic Response Spectra with soil amplification coefficients.

Soil shear velocities (Vs) are generally categorized in codes with respect to their magnitudes in four intervals which are $\mathrm{V}_{\mathrm{s}}<180 \mathrm{~m} / \mathrm{s}, 180 \mathrm{~m} / \mathrm{s}<\mathrm{V}_{\mathrm{s}}<360 \mathrm{~m} / \mathrm{s}$, $360 \mathrm{~m} / \mathrm{s}<\mathrm{V}_{\mathrm{s}}<800 \mathrm{~m} / \mathrm{s}$ and $800 \mathrm{~m} / \mathrm{s}<\mathrm{V}_{\mathrm{s}}<1600 \mathrm{~m} / \mathrm{s}$.

Soil amplification factor used in AzDTN at lower shear velocities are generally higher than others except Snip's. Therefore, the AzDTN elastic spectrum for Vs smaller than $180 \mathrm{~m} / \mathrm{s}$ becomes higher than other spectra (Figure 2(a)). When the soil shear velocities are between $180 \mathrm{~m} / \mathrm{s}<\mathrm{V}_{\mathrm{s}}<360 \mathrm{~m} / \mathrm{s}$, AzDTN spectrum gives similar values at lower periods like BCJ, EC8 and UBC97/IBC2006 except Snip, but it gives larger values than others at higher periods (Figure 2 (b)). Soil classes in Azerbaijan generally exist "II" according to soil investigation results and their shear velocities vary between $360 \mathrm{~m} / \mathrm{s}<\mathrm{V}_{\mathrm{s}}<800 \mathrm{~m} / \mathrm{s}$ in which range AzDTN elastic spectrum give similar values as other codes up to 2 second, but gives higher values after this period. On the other hand, when soil shear velocities are between $800 \mathrm{~m} / \mathrm{s}<\mathrm{V}_{\mathrm{s}}<1600 \mathrm{~m} / \mathrm{s}$, AzDTN has lower elastic spectrum values than other seismic codes except for Snip at lower period but it is nearly the same as others at higher periods. 


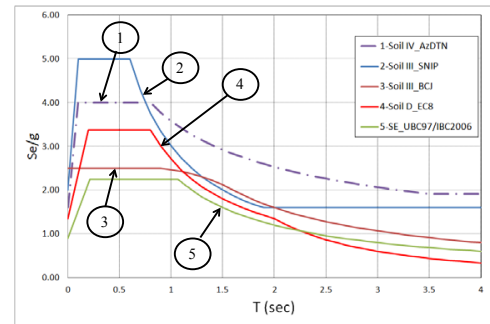

a) $\mathrm{V}_{\mathrm{s}}<180 \mathrm{~m} / \mathrm{s}$

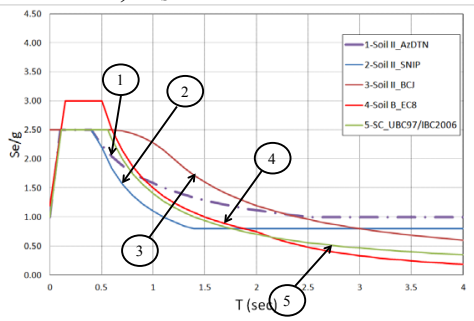

c) $360 \mathrm{~m} / \mathrm{s}<\mathrm{V}_{\mathrm{s}}<800 \mathrm{~m} / \mathrm{s}$

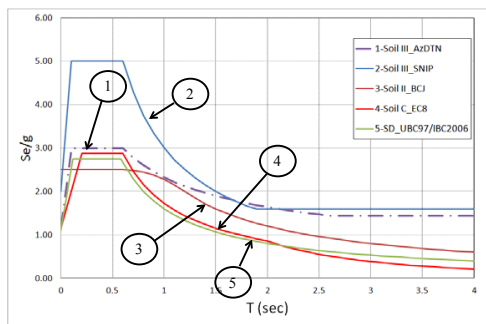

b) $180 \mathrm{~m} / \mathrm{s}<\mathrm{V}_{\mathrm{s}}<360 \mathrm{~m} / \mathrm{s}$

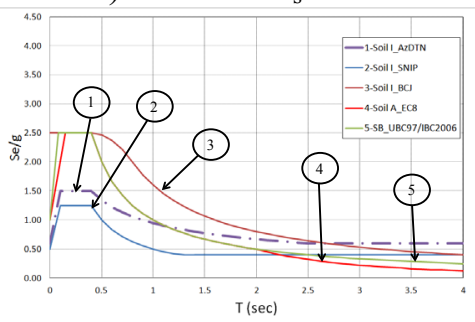

d) $800 \mathrm{~m} / \mathrm{s}<V_{\mathrm{s}}<1600 \mathrm{~m} / \mathrm{s}$

Figure 2: Unreduced Elastic Response Spectra Comparison for different shear wave velocities.

\section{Equivalent seismic base shear coefficients}

7-story and 16-story-buildings with moment resisting frame structural systems are examined and compared herein according to AzDTN and other seismic codes using equivalent base shear method. It is assumed in the base shear calculations that these buildings are to be designed in Baku, principal city of Azerbaijan.

Seismic intensity of Baku as per AzDTN and Snip are defined " 8 " and corresponding peak ground acceleration on bedrock are specified as $0.25 \mathrm{~g}$ and $0.2 \mathrm{~g}$, respectively. Seismic zone of Baku is defined in UBC97 as 3 and corresponding PGA value is $0.3 \mathrm{~g}$. In addition, $\mathrm{S}_{\mathrm{S}}$ and $\mathrm{S}_{1}$ values for Baku as per IBC2006/2009 specified in Overseas Building Operations (OBO) [11] supplement to IBC are 1.12 and 0.45 which are updated values for Baku. These updated spectral response values are used during the code comparison calculation for UBC97/IBC2006 base shear calculations. EC8 does not specify any PGA values for any places, because it refers to local codes. Baku's PGA value of $0.25 \mathrm{~g}$ then is taken from local code (AzDTN) for these buildings and the seismic base shear calculations are carried out. Zoning coefficients are defined in BSL code for Japanese territories. The zoning coefficient of 1 is obtained in the code by multiplying $0.4 \mathrm{~g}$ (PGA) with 2.5 . Using this assumption, zoning factor of Baku as per BSL code can be calculated as 0.625 (by multiplying 0.25 (from the local code) $\times 2.5$ ).

Soil type and soil amplification factors change with reference to codes. In order to carry out consistent seismic base shear coefficient comparisons, it is assumed herein that the soil shear velocity for these 7-story and 16-story 
building ranges from $600 \mathrm{~m} / \mathrm{s}$ and $800 \mathrm{~m} / \mathrm{s}$. The design seismic load and seismic base shear coefficient $\left(\mathrm{C}_{\mathrm{s}}\right)$ is calculated according to AzDTN and other codes as follows

\section{Seismic Base Shear Coefficient according to AzDTN}

$$
\begin{gathered}
\mathrm{S}_{\mathrm{ik}}=\mathrm{k}_{1} \cdot \mathrm{k}_{2} \cdot \mathrm{k}_{3} \cdot \mathrm{k}_{\psi} \cdot \mathrm{k}_{\mathrm{q}} \cdot \mathrm{a}_{0} \cdot \beta_{\mathrm{i}} \cdot \eta_{\mathrm{ik}} \cdot \mathrm{Q}_{\mathrm{k}} \\
\mathrm{S}_{\mathrm{ik}}=\mathrm{C}_{\mathrm{s}_{-} \text {AzDTN }} \cdot \mathrm{Q}_{\mathrm{k}}
\end{gathered}
$$

where $\mathrm{k}_{1}$ is the importance factor ranging between 0.5 and $3.0, \mathrm{k}_{2}$ is the behavior factor (Table 2), $\mathrm{k}_{3}$ is the story amplification factor $\left(k_{3}=1+0.02\right.$ (story number-5); $1.0 \leq k_{3} \leq 1.5$ ), $\mathrm{k}_{\psi}$ is the dimension factor ranging between 1.0 and $1.3, \mathrm{Q}_{\mathrm{k}}$ is the total weight of the building/structure, $\mathrm{k}_{\mathrm{q}}$ is the soil amplification factor ranging between 0.6 and 1.6, $\mathrm{a}_{\mathrm{o}}$ is the ground acceleration (Table 10), $\beta_{\mathrm{i}}$ is the elastic response spectrum, and $\eta_{\mathrm{ik}}$ is horizontal distribution factor.

Table 10: $\quad$ Peak ground acceleration values (PGA) as per AzDTN.

\begin{tabular}{c|c}
\hline Seismic Intensity & $\mathrm{a}_{0}$ \\
\hline 7 & 0.125 \\
\hline 8 & 0.25 \\
\hline 9 & 0.5 \\
\hline 10 & 1.0 \\
\hline
\end{tabular}

Seismic Base Shear Coefficient according to SNiP II-7-81

$$
\begin{gathered}
\mathrm{S}_{\mathrm{ik}}=\mathrm{k}_{1} \cdot \mathrm{k}_{2} \cdot \mathrm{A} \cdot \mathrm{k}_{\psi} \beta_{\mathrm{i}}\left(\eta_{\mathrm{ik}} \cdot \mathrm{Q}_{\mathrm{k}}\right) \\
\mathrm{S}_{\mathrm{ik}}=\mathrm{C}_{\mathrm{s}_{-} \text {Snip }} \cdot \mathrm{Q}_{\mathrm{k}}
\end{gathered}
$$

where $\mathrm{k}_{1}$ is the behavior factor, $\mathrm{k}_{2}$ is the story amplification factor $\left(k_{2}=1+0.1\right.$ (story number-5); $1.0 \leq k_{2} \leq 1.5$ ), A is the peak ground acceleration , $\mathrm{k}_{\psi}$ is the dimension factor $\left(1.0 \leq \mathrm{k}_{\psi} \leq 1.5\right)$, and $\mathrm{Q}_{\mathrm{k}}$ is the weight of the building/structure.

Seismic Base Shear Coefficient according to BSL

$$
\begin{gathered}
\mathrm{Q}_{\mathrm{i}}=\mathrm{D}_{\mathrm{s}} \cdot \mathrm{F}_{\mathrm{es}} \cdot \mathrm{Z} \cdot \mathrm{R}_{\mathrm{t}} \cdot \mathrm{C} \cdot \mathrm{W}_{\mathrm{i}} \\
\mathrm{Q}_{\mathrm{i}}=\mathrm{C}_{\mathrm{s}_{-} \mathrm{BSL}} \cdot \mathrm{W}_{\mathrm{i}}
\end{gathered}
$$

where $D_{s}$ is the structural characteristics factor, $F_{e s}$ is the shape factor, $C$ is the standard shear coefficient (1.0 for severe earthquake), $\mathrm{Z}$ is the zoning coefficient, $\mathrm{Wi}$ is the total mass of the building/structure, and $\mathrm{R}_{\mathrm{t}}$ is the elastic spectra.

\section{Seismic Base Shear Coefficient according to EC8}

$$
\begin{gathered}
\mathrm{F}_{\mathrm{b}}=\mathrm{S}_{\mathrm{e}}\left(\mathrm{T}_{1}\right) \cdot \mathrm{I} \cdot \mathrm{m} \cdot \lambda / \mathrm{q} \\
\mathrm{F}_{\mathrm{b}}=\mathrm{C}_{\mathrm{s}_{\mathrm{E}} \mathrm{EC} 8} \cdot \mathrm{W}
\end{gathered}
$$

where $\mathrm{Se}(\mathrm{T} 1)$ is the elastic response spectrum, $\mathrm{a}_{\mathrm{g}}$ is the design ground acceleration, $S$ is the soil factor, $\eta$ is the damping correction factor $(\eta=1$ for $5 \%$ 
viscous damping), $\mathrm{I}$ is the importance classes, $\mathrm{m}$ is the total mass of the building, $\lambda$ is the correction factor. $\lambda=0.85$ if $\mathrm{T}_{1}<2 \mathrm{~T}_{\mathrm{c}}$ or $\lambda=1.0$, and $\mathrm{q}$ is the behavior factor.

\section{Seismic Base Shear Coefficient according to UBC97/IBC 2006}

$$
C_{s_{-} U B C 97 / I B C 2006=} \frac{S_{D 1}}{T x \frac{R}{I_{e}}} \quad \text { for } \mathrm{T}<\mathrm{T}_{\mathrm{L}}
$$

where $\mathrm{S}_{\mathrm{D} 1}$ is the design spectral acceleration parameter at a period of $1.0 \mathrm{sec}, \mathrm{T}$ is the fundamental period of structure, $\mathrm{R}$ is the response modification factor and $\mathrm{I}$ is the structure importance factor.

Table 11: $\quad$ Base shear coefficient (Cs) of 7-story building.

\begin{tabular}{|c|c|c|c|c|c|c|c|c|c|}
\hline \multicolumn{2}{|c|}{ AzDTN } & \multicolumn{2}{|c|}{ SNIP } & \multicolumn{2}{|c|}{ BSL } & \multicolumn{2}{|c|}{$\mathrm{EC} 8$} & \multicolumn{2}{|c|}{ UBC97/IBC2006 } \\
\hline Factors & 7 story & Factors & 7 story & Factors & 7 story & Factors & 7_story & Factors & 7_story \\
\hline $\mathrm{k} 1$ & 1 & $\mathrm{k} 1$ & 0.25 & Ds & 0.3 & $\mathrm{a}_{\mathrm{g}}$ & 0.25 & $\mathrm{~S}_{\mathrm{D} 1}$ & 0.405 \\
\hline $\mathrm{k} 2$ & 0.35 & $\mathrm{k} 2$ & 1.2 & Fes & 1 & $\mathrm{~S}$ & 1.15 & $\mathrm{R}$ & 8 \\
\hline $\mathrm{k} 3$ & 1.04 & $\mathrm{k} \Psi$ & 1 & $\mathrm{Z}$ & 0.625 & $\eta$ & 1 & $\mathrm{I}$ & 1 \\
\hline $\mathrm{k} \Psi$ & 1 & $\mathrm{a}_{0}$ & 0.2 & $\mathrm{Rt}$ & 0.995 & $\lambda$ & 0.85 & & \\
\hline $\mathrm{kq}$ & 1 & $\beta$ & 1.571429 & $\mathrm{C}$ & 1 & $\mathrm{I}$ & 1 & & \\
\hline $\mathrm{a}_{0}$ & 0.25 & & & & & $q$ & 3.9 & & \\
\hline$\beta$ & 1.89 & & & & & & & & \\
\hline $\mathrm{C}_{\mathrm{s} \text { AzDTN }}$ & 0.172 & $\mathrm{C}_{\mathrm{s} \text { Snip }}$ & 0.094 & $\mathrm{C}_{\mathrm{s} \text { BSL }}$ & 0.187 & $\mathrm{C}_{\mathrm{S} \text { EC } 8}$ & 0.099 & $\mathrm{C}_{\mathrm{s} \text { UBC97 }}$ & 0.064 \\
\hline
\end{tabular}

Table 12: $\quad$ Base shear coefficient $\left(\mathrm{C}_{\mathrm{s}}\right)$ of 16-story building.

\begin{tabular}{|c|c|c|c|c|c|c|c|c|c|}
\hline \multicolumn{2}{|c|}{ AzDTN } & \multicolumn{2}{|c|}{ SNIP } & \multicolumn{2}{|c|}{ BSL } & \multicolumn{2}{|c|}{ EC8 } & \multicolumn{2}{|c|}{ UBC97/IBC2006 } \\
\hline Factors & 16 story & Factors & 16 story & Factors & 16 story & Factors & 16 story & Factors & 16 story \\
\hline k1 & 1 & $\mathrm{k} 1$ & 0.25 & Ds & 0.3 & $\mathrm{a}_{\mathrm{g}}$ & 0.25 & $\mathrm{~S}_{\mathrm{D} 1}$ & 0.405 \\
\hline $\mathrm{k} 2$ & 0.3 & $\mathrm{k} 2$ & 1.5 & Fes & 1 & $\mathrm{~S}$ & 1.15 & $\mathrm{R}$ & 8 \\
\hline k3 & 1.22 & $\mathrm{k} \Psi$ & 1 & $\mathrm{Z}$ & 0.625 & $\eta$ & 1 & I & 1 \\
\hline $\mathrm{k} \Psi$ & 1 & $\mathrm{a}_{0}$ & 0.2 & Rt & 0.606 & $\lambda$ & 1 & & \\
\hline $\mathrm{kq}$ & 1 & $\beta$ & 0.8 & $\mathrm{C}$ & 1 & I & 1 & & \\
\hline $\mathrm{a}_{0}$ & 0.25 & & & & & $\mathrm{q}$ & 3.9 & & \\
\hline$\beta$ & 1.25 & & & & & & & & \\
\hline $\mathrm{C}_{\mathrm{s} \text { AzDTN }}$ & 0.114 & $\mathrm{C}_{\mathrm{s} \text { Snip }}$ & 0.060 & $\mathrm{C}_{\mathrm{s} \text { BSL }}$ & 0.114 & $\mathrm{C}_{\mathrm{S} \text { EC } 8}$ & 0.063 & $\mathrm{C}_{\mathrm{s}} \mathrm{UBC} 97$ & 0.031 \\
\hline
\end{tabular}

\section{Summary and conclusion}

This paper examines and compares the provisions stipulated in Azerbaijan Seismic Code (AzDTN) against USSR (Snip), Japanese (BSL), European (EC8) and American (UBC97/IBC2006) seismic codes. Soil shear wave velocity, unreduced elastic spectra and seismic base shear coefficient for 7- and 16-story 
buildings with moment resisting frames are compared. Major conclusions are as follows.

1) Soil classifications based on Soil Shear Wave Velocity (Vs) and Standard Penetration Test Results (NSPT) in AzDTN are relatively similar to ones in Snip, EC8 and UBC97/IBC2006 but they are different to BSL soil classifications.

2) The behavior factors are smaller in AzDTN than EC8 and UBC97/IBC2006 but are similar to Snip and BSL. This indicates that a lot of conceptual difference regarding strength and ductility exists between codes.

3) Unreduced Elastic Spectrum of AzDTN at the small shear wave velocity $(\mathrm{Vs}<180 \mathrm{~m} / \mathrm{s})$ which is for soft soils are larger (approximately twice) than ones of BSL, EC8 and UBC97/2006. On the other hand, it smaller at lower periods but relatively same as with other codes at higher periods when shear wave velocity is between $800 \mathrm{~m} / \mathrm{s}$ and $1600 \mathrm{~m} / \mathrm{s}$.

4) When shear wave velocity is between $180 \mathrm{~m} / \mathrm{s}$ and $800 \mathrm{~m} / \mathrm{s}$, Unreduced Elastic Spectra of AzDTN are close to BSL, EC8 and UBC97/IBC2006 at lower periods but are larger than other codes at higher periods.

5) Seismic base shear coefficients of 7-story and 16-story buildings calculated according to AzDTN's provisions are similar to the coefficient according to BSL but larger than other codes (Figure 3).

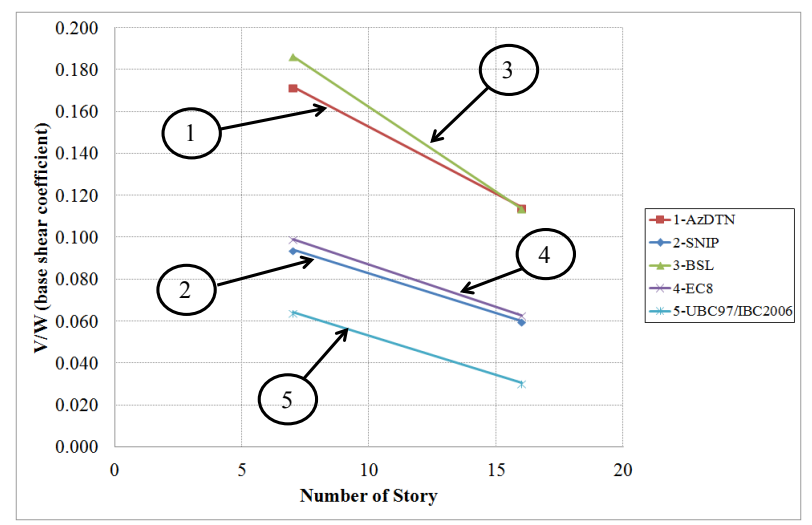

Figure 3: $\quad$ Seismic base shear coefficients of 7-story and 16-story-buildings.

\section{References}

[1] General Information on the Nature of Azerbaijan http://www.azerbaijan.az /_Geography/_GeneralInfo/_generalInfo_e.html

[2] SNiP II-7-81*, Construction in Seismic Areas. Moscow, 1981 (addition 1991) (in Russian). 
[3] AzDTN 2.3-1, Construction in Seismic Areas, 2009 (in Azerbaijani).

[4] L.M.Zeynalov. About specifying of seismic impacts to the high rise building frames. AzUAC, Scientific-technical Journal between universities. Collection of scientific works on mechanics, Baku 2003 (in Azerbaijani).

[5] L.M.Zeynalov, One more time about specifying problems of seismic affects. Scientific-technical Journal between universities. Applied Mechanics No-1, Baku 2005 (in Azerbaijani).

[6] BSL The Building Standard Law of Japan, 2011.

[7] EuroCode 8, Design of Structure for Earthquake Resistance - Part 1: General Rules, seismic actions and rules for buildings, December 2004.

[8] UBC97, Uniform Building Code, Volume 2.

[9] IBC2006, International Building Code.

[10] Y.Ishiyama, Seismic Codes for Buildings in Japan, Tokyo. 2011.

[11] OBO, Building Code of Overseas Buildings Operations, Supplement to 2009 International Building Code (IBC), 2011. 